\title{
Preparation and Properties of Rhodium(III) Complexes with the Tetradentate Ligand $\mathrm{N}, \mathrm{N}^{\prime}$-Bis(2'-pyridinecarboxamide)-1,8-naphthalene
}

\author{
Evy Manessi-Zoupa, Theodoros F. Zafiropoulos*, Spyros P. Perlepes* \\ Laboratory of Inorganic Chemistry, Department of Chemistry, University of Patras, \\ Patras, Greece
}

Z. Naturforsch. 49b, 111- 118 (1994); received June 14, 1993

Rhodium(III) Complexes, Bis-amide Ligands, IR Spectra, ${ }^{1} \mathrm{H}$ NMR Spectra,

Cyclic Voltammetry

Synthetic procedures are described that allow access to a number of new $\mathrm{Rh}(\mathrm{III})$ complexes with the tetradentate bis-amide ligand $\mathrm{N}, \mathrm{N}^{\prime}$-bis (2'-pyridinecarboxamide)-1,8-naphthalene $\left(\mathrm{LH}_{2}\right)$. These complexes have the formulae $\mathrm{Rh}\left(\mathrm{LH}_{2}\right) \mathrm{Cl}_{3}, \mathrm{Na}\left[\mathrm{RhLX}_{2}\right] \cdot \mathrm{H}_{2} \mathrm{O}(\mathrm{X}=\mathrm{Cl}, \mathrm{CN})$ and $\left[\mathrm{RhLA}_{2}\right] \mathrm{ClO}_{4}(\mathrm{~A}=$ pyridine, 1-methylbenzotriazole $)$. The compounds have been characterized by elemental analyses, conductivity measurements, X-ray powder patterns, spectroscopic (IR, UV/VIS, ${ }^{1} \mathrm{H}$ NMR) studies and electrochemical methods. The neutral amide behaves as a bisbidentate ligand in the oligomeric or polymeric, octahedral complex $\mathrm{Rh}\left(\mathrm{LH}_{2}\right) \mathrm{Cl}_{3}$. Monomeric, trans octahedral structures are assigned for the complexes of $\mathrm{L}^{2-}$ in the solid state; the doubly deprotonated ligand acts as a tetradentate chelating agent with the four nitrogens as ligating atoms.

\section{Introduction}

The coordination chemistry of organic amide ligands plays an important role in inorganic chemistry [1], ranging from solution chemistry [2, 3] to biological modeling $[4,5]$ and materials chemistry $[6,7]$. In contrast to the large number of studies concerning $3 \mathrm{~d}$ metal-amide complexes, little is known about the corresponding complexes with $4 \mathrm{~d}$ and $5 \mathrm{~d}$ metals [1]; exceptions are $\mathrm{Pd}^{\mathrm{II}}$ and $\mathrm{Pt}^{\mathrm{II}}$ complexes.

As part of our systematic investigation on the coordinating properties of the amide bond [8-18], we report here the preparation and detailed characterization of rhodium(III) complexes with the bis-amide tetradentate ligand $\mathrm{N}, \mathrm{N}^{\prime}$-bis $(2$ '-pyridinecarboxamide)-1,8-naphthalene ( $\left.\mathrm{I}, \mathrm{LH}_{2}\right)$. Until now, with the exception of the work of Che and co-workers [19], no Rh(III) complexes with bisamide ligands have been investigated. One of the driving forces behind our current interest in rhodium-amide chemistry is the fact that dianionic, pyridine-containing, bis-amide ligands are capable of stabilizing transition-metal ions in high oxidation states $[2,19,20]$; the exciting possibility to

\footnotetext{
* Reprint requests to Prof. Dr. Th. F. Zafiropoulos or Dr. S. P. Perlepes.
}

Verlag der Zeitschrift für Naturforschung, D-72072 Tübingen

$0932-0776 / 94 / 0100-0111 / \$ 01.00 / 0$ generate stable Rh(IV) species was one of the stimuli for this work. The ligand $\mathrm{LH}_{2}$ has been shown to coordinate to $3 \mathrm{~d}$ [21-24], Pd(II), Pt(II) $[25]$ and $4 \mathrm{f}[26,27]$ metals in several modes, largely determined by the nature of the metal and the anion present, and by the preparative conditions.

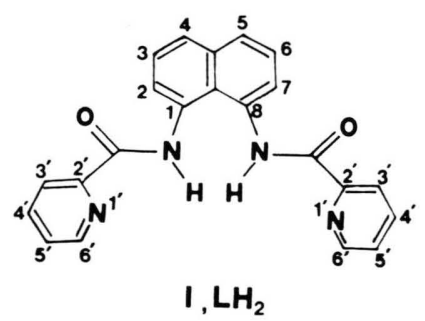

\section{Experimental}

All synthetic operations were performed under aerobic conditions. The starting material $\mathrm{RhCl}_{3} \cdot 3 \mathrm{H}_{2} \mathrm{O}$ was purchased from Merck. $\mathrm{LH}_{2}$ was synthesized as described earlier [21]; its purity was checked by microanalyses and ${ }^{1} \mathrm{H}$ NMR spectroscopy. The solvents and chemicals used were of reagent grade, without further purification. In electrochemical work, $\mathrm{MeCN}$ was dried and distilled over powdered $\mathrm{CaH}_{2} \cdot \mathrm{N}^{n} \mathrm{Bu}_{4} \mathrm{BF}_{4}$ (Merck) was dried at $95^{\circ} \mathrm{C}$ in a vacuum for $48 \mathrm{~h}$ before use. All solutions for electrochemical studies were deaerated with high-purity Ar. Physicochemical measurements and spectroscopic techniques were carried out by published methods [15, 28, 29]. 
$\left\{\left[\mathrm{Rh}\left(\mathrm{LH}_{2}\right) \mathrm{Cl}_{2}\right] \mathrm{Cl}\right\} n(\mathbf{1})$

A solution of $\mathrm{RhCl}_{3} \cdot 3 \mathrm{H}_{2} \mathrm{O}(0.26 \mathrm{~g}, 1.0 \mathrm{mmol})$ in $\mathrm{MeOH}(25 \mathrm{ml})$ was added dropwise to a stirred warm solution of $\mathrm{LH}_{2}(0.37 \mathrm{~g}, 1.0 \mathrm{mmol})$ in the same solvent $(30 \mathrm{ml})$. Upon addition of the metal salt a yellow precipitate was formed. Stirring was continued for $12 \mathrm{~h}$ at room temperature. The precipitate was filtered off, washed with EtOH $(2 \times 5$ $\mathrm{ml})$ and $\mathrm{Et}_{2} \mathrm{O}(3 \times 10 \mathrm{ml})$, and dried in vacuo over silica gel. Yield: $c a .95 \%$.

\section{Analyses for $\mathrm{C}_{22} \mathrm{H}_{16} \mathrm{~N}_{4} \mathrm{O}_{2} \mathrm{RhCl}_{3}$}

Calcd C $45.74 \mathrm{H} 2.80 \mathrm{~N} 9.70 \mathrm{Cl} 18.41 \%$,

Found C 46.03 H 2.71 N 9.63 Cl 17.93\%.

The molar conductance $\left(\Lambda_{\mathrm{M}}\right)$ value for a $c a$. $1 \times 10^{-3} \mathrm{M}$ DMSO solution at $25^{\circ} \mathrm{C}$ was $34 \mathrm{~S} \mathrm{~cm}^{2}$ $\mathrm{mol}^{-1}$.

\section{$\mathrm{Na}\left[\mathrm{RhLCl}_{2}\right] \cdot \mathrm{H}_{2} \mathrm{O}(\mathbf{2})$}

$\mathrm{LH}_{2}(0.37 \mathrm{~g}, 1.0 \mathrm{mmol})$ was slowly added to a solution of $\mathrm{RhCl}_{3} \cdot 3 \mathrm{H}_{2} \mathrm{O}(0.26 \mathrm{~g}, 1.0 \mathrm{mmol})$ in $\mathrm{MeOH}(30 \mathrm{ml})$. A yellow precipitate was immediately obtained. The reaction mixture was stirred while a solution of $\mathrm{NaOH}(0.08 \mathrm{~g}, 2.0 \mathrm{mmol})$ in $\mathrm{H}_{2} \mathrm{O}(5 \mathrm{ml})$ was added in small portions over approximately $10 \mathrm{~min}$; during the alkali addition the colour changed to red. Overnight reflux gave a red-orange precipitate, which was collected by filtration and redissolved in $\mathrm{MeCN}(30 \mathrm{ml})$. Layering of this solution with an equal volume of $\mathrm{Et}_{2} \mathrm{O}$ gave, after several days, orange-red flakes, which were isolated by filtration, washed with $\mathrm{Et}_{2} \mathrm{O}$ and dried in air. Yield: $c a .35 \%$.

Analyses for $\mathrm{C}_{22} \mathrm{H}_{16} \mathrm{~N}_{4} \mathrm{O}_{3} \mathrm{RhNaCl}$ Calcd C $45.46 \mathrm{H} 2.78 \mathrm{~N} 9.64 \mathrm{Cl} 12.20 \%$, Found C 45.33 H 2.69 N $9.80 \mathrm{Cl} 13.01 \%$. $\Lambda_{\mathrm{M}}\left(\mathrm{MeCN}, 10^{-3} \mathrm{M}, 25^{\circ} \mathrm{C}\right): 128 \mathrm{~S} \mathrm{~cm}^{2} \mathrm{~mol}^{-1}$.

$\mathrm{Na}\left[\mathrm{RhL}(\mathrm{CN})_{2}\right] \cdot \mathrm{H}_{2} \mathrm{O}(\mathbf{3})$

To a solid mixture containing complex $2(0.25 \mathrm{~g}$, $0.43 \mathrm{mmol})$ and excess $\mathrm{NaCN}(0.10 \mathrm{~g}, 2.05 \mathrm{mmol})$ was added $\mathrm{MeOH}(40 \mathrm{ml})$. The resulting orange slurry was refluxed for a few hours to yield an intense yellow solution and some white precipitate. The latter was removed by filtration and the filtrate refrigerated $\left(-20^{\circ} \mathrm{C}\right)$ for $48 \mathrm{~h}$. The resulting yellow microcrystalline solid was collected by filtration and washed with $\mathrm{Et}_{2} \mathrm{O}$. The solid was purified by dissolution in $\mathrm{MeOH}(30 \mathrm{ml})$, followed by filtration, addition of $30 \mathrm{ml}$ of acetone- $\mathrm{Et}_{2} \mathrm{O}$ $(50: 50, v / v)$, and overnight storage of the solution at $-5{ }^{\circ} \mathrm{C}$. The product was isolated by filtration, washed with $n$-hexane and dried in air. Yield: $c a$. $40 \%$.

Analyses for $\mathrm{C}_{24} \mathrm{H}_{16} \mathrm{~N}_{6} \mathrm{O}_{3} \mathrm{RhNa}$

Calcd C 51.26 H 2.87

Found C 51.01 H 2.96 N 14.27\%.

$\Lambda_{\mathrm{M}}\left(\mathrm{MeCN}, 10^{-3} \mathrm{M}, 25^{\circ} \mathrm{C}\right): 140 \mathrm{~S} \mathrm{~cm}^{2} \mathrm{~mol}^{-1}$. $\Lambda_{\mathrm{M}}\left(\mathrm{MeOH}, 10^{-3} \mathrm{M}, 25^{\circ} \mathrm{C}\right): 74 \mathrm{~S} \mathrm{~cm}^{2} \mathrm{~mol}^{-1}$.

\section{$\left[\mathrm{RhL}(\mathrm{Py})_{2}\right] \mathrm{ClO}_{4}(\mathbf{4})$}

A slurry of complex $1(0.25 \mathrm{~g})$ in EtOH $(50 \mathrm{ml})$ was treated with an excess of pyridine (Py) $(1.2 \mathrm{ml})$ and $\mathrm{Zn}$ powder $(0.12 \mathrm{~g})$. The reaction mixture was heated for $15 \mathrm{~min}$ at $55^{\circ} \mathrm{C}$ and evaporated to dryness. The crude product was extracted into $\mathrm{CH}_{2} \mathrm{Cl}_{2}-\mathrm{MeOH}(\mathrm{ca} .40: 60, \mathrm{v} / \mathrm{v})$, the solution filtered and an excess of $\mathrm{LiClO}_{4} \cdot 3 \mathrm{H}_{2} \mathrm{O}$, dissolved in the minimum volume of $\mathrm{MeOH}$, added. After overnight storage in a freezer, the resulting orange powder was collected by filtration, washed with $\mathrm{Et}_{2} \mathrm{O}$ and dried in vacuo. The product was purified by two cycles of dissolution in $\mathrm{MeCN}$ and precipitation by $\mathrm{Et}_{2} \mathrm{O}$. Yields were typically in the $20-30 \%$ range.

Analyses for $\mathrm{C}_{32} \mathrm{H}_{24} \mathrm{~N}_{6} \mathrm{O}_{6} \mathrm{RhCl}$

Calcd C 52.87 H 3.33 N $11.56 \%$,

Found C 53.01 H 3.48 N 11.17\%.

$\Lambda_{\mathrm{M}}\left(\mathrm{MeCN}, 10^{-3} \mathrm{M}, 25^{\circ} \mathrm{C}\right): 128 \mathrm{~S} \mathrm{~cm}^{2} \mathrm{~mol}^{-1}$.

\section{$\left[\mathrm{RhL}(\mathrm{Mebta})_{2}\right]_{\mathrm{ClO}_{4}}(\mathbf{5})$}

This orange solid was prepared by reacting compound $1(0.25 \mathrm{~g}, 0.43 \mathrm{mmol})$ with excess 1-methylbenzotriazole (II, Mebta) and $\mathrm{LiClO}_{4} \cdot 3 \mathrm{H}_{2} \mathrm{O}$, in the presence of $\mathrm{Zn}$ powder $(0.12 \mathrm{~g})$ and the strictly stoichiometric (for the removal of the two amide hydrogens of $\left.\mathrm{LH}_{2}\right)$ amount of Py $(0.07 \mathrm{ml}, 0.87$ $\mathrm{mmol}$ ) in a manner similar to the procedure described above for $\mathbf{4}$. The product was isolated and purified using the same solvents and procedures as above. Yield: $c a$. $20 \%$.

Analyses for $\mathrm{C}_{36} \mathrm{H}_{28} \mathrm{~N}_{10} \mathrm{O}_{6} \mathrm{RhCl}$

Calcd C 51.77 H 3.39 N 16.78\%,

Found C 51.91 H 3.50 N 15.99\%.

$\Lambda_{\mathrm{M}}(\mathrm{MeCN}): 119 \mathrm{~S} \mathrm{~cm}^{2} \mathrm{~mol}^{-1}$.

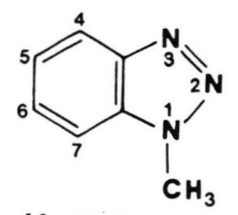

II, Mebta 
Caution! Perchlorate salts are potentially explosive. Although no detonation tendencies have been observed in the synthetic work, caution is advised and handling of only small quantities is recommended.

\section{Results and Discussion}

The Experimental Section lists five Rh(III) complexes in order of time of their preparation. The formation of some representative compounds can be summarized in eq. (1)-(3):

$$
\begin{aligned}
& n \mathrm{RhCl}_{3} \cdot 3 \mathrm{H}_{2} \mathrm{O}+n \mathrm{LH}_{2} \stackrel{\mathrm{MeOH}}{\longrightarrow} \\
& \left.\left\{\left[\mathrm{Rh}_{2} \mathrm{LH}_{2}\right) \mathrm{Cl}_{2}\right] \mathrm{Cl}\right\}_{n}+3 n \mathrm{H}_{2} \mathrm{O} \\
& \\
& \mathrm{RhCl} \cdot 3 \mathrm{H}_{2} \mathrm{O}+\mathrm{LH}_{2}+2 \mathrm{NaOH} \stackrel{\mathrm{MeOH}-\mathrm{H}_{2} \mathrm{O}}{\text { reflux }} \\
& \mathrm{Na}[\mathrm{RhLCl}] \cdot \mathrm{H}_{2} \mathrm{O}+\mathrm{NaCl}+4 \mathrm{H}_{2} \mathrm{O}
\end{aligned}
$$

$$
\begin{aligned}
& \left\{\left[\mathrm{Rh}\left(\mathrm{LH}_{2}\right) \mathrm{Cl}_{2}\right] \mathrm{Cl}\right\}_{n}+4 n \mathrm{Py}+n \mathrm{LiClO}_{4} \cdot 3 \mathrm{H}_{2} \mathrm{O} \\
& \text { EtOH-MeOH}-\mathrm{CH}_{2} \mathrm{Cl}_{2} \\
& \mathrm{Zn} \text {, exc. Py } \\
& n\left[\mathrm{RhL}(\mathrm{Py})_{2}\right] \mathrm{ClO}_{4}+n \mathrm{LiCl}+2 n \mathrm{PyHCl}+3 n \mathrm{H}_{2} \mathrm{O}
\end{aligned}
$$

A few synthetic points deserve comments. First, the nearly quantitative yield in the preparation of $\mathbf{1}$ is a strong evidence that this compound is oligomeric or polymeric. Second, it appears that the anions trans- $\left[\mathrm{RhLCl}_{2}\right]^{-}$is the thermodynamically preferred species in aqueous methanol (at $\sim$ neutral $\mathrm{pH})$ in the absence of strong axial ligands, which can be used as a starting material for the synthesis of analogous products. For example, we anticipated that complex $\mathbf{2}$ should undergo chloro substitution on treatment with an excess of strong axial ligands and have confirmed this by preparing complex 3. Third, in the syntheses of the cationic complexes $\mathbf{4}$ and $\mathbf{5}$ the reaction is accelerated by the presence of $\mathrm{Zn}$ powder; presumably, a Rh(I) species generated in situ catalyses the substitution reactions. This parallels the behaviour observed for the $\mathrm{Rh}(\mathrm{III}) / 1,2$-bis(2'-pyridinecarboxamido)benzene/Py complexes [19]. A final point of interest is the use of $\mathrm{LiClO}_{4}$ in the preparation of $\mathbf{4}$ and 5. The use of $\mathrm{LiClO}_{4}$ as the source of counterions, instead of $\mathrm{NaClO}_{4}$ or $\mathrm{KClO}_{4}$, gives good results because $\mathrm{LiClO}_{4}$ and $\mathrm{LiCl}$ (a product of the reactions) are both soluble in the solvent mixture used and, thus, $\mathbf{4}$ and $\mathbf{5}$ are not contaminated.
The isolated compounds are microcrystalline or powder-like and stable under atmospheric conditions. Complex $\mathbf{1}$ is slightly soluble only in DMSO. Complexes 2-5 are soluble in polar organic solvents, but to varying extents. The complexes have a moderate solubility in $\mathrm{H}_{2} \mathrm{O}$; however, their aqueous solutions are not stable. We had hoped to structurally characterize one of the complexes of $\mathrm{L}^{2-}$ by X-ray crystallography (working mainly with $\mathrm{MeCN}$ and DMF), but were thwarted on numerous occasions by twinning problems or lack of single crystals. Thus, the characterization of the complexes is based on other physical techniques and on spectroscopic methods.

The molar conductance values of 2-5 in $\mathrm{MeCN}$ and $\mathrm{MeOH}$ lie in the ranges observed for $1: 1$ electrolytes [30]. The $\Lambda_{M}$ value of $\mathbf{1}$ in DMSO is also in accord with this compound being formulated as a $1: 1$ electrolyte [30].

$\mathrm{X}$-ray powder diffraction patterns in the $4^{\circ}<2 \theta<60^{\circ}$ range indicate that each solid represents a definite compound, which is not contaminated with starting materials or/and byproducts.

All the prepared complexes are diamagnetic.

The thermal decomposition of the complexes was studied using TG/DTG, DTA and DSC techniques. The TG/DTG curves of $\mathbf{2}$ and $\mathbf{3}$ show a first, endothermic mass loss at 80-125 and $70-115^{\circ} \mathrm{C}$, respectively, which corresponds to the release of the water content; the relatively low temperature of $\mathrm{H}_{2} \mathrm{O}$ loss indicates that this is lattice held. Clear plateaux are reached at about 130 and $120^{\circ} \mathrm{C}$ for $\mathbf{2}$ and $\mathbf{3}$, respectively, suggesting that the anhydrous species are thermally stable. The activation energy values $E_{a}$ of the dehydration reactions were

$\underset{(\mathrm{X}=\mathrm{Cl}, \mathrm{CN})}{\mathrm{Na}\left[\mathrm{RhLX}_{2}\right] \cdot \mathrm{H}_{2} \mathrm{O} \stackrel{\mathrm{T}}{\longrightarrow} \mathrm{Na}\left[\mathrm{RhLX}_{2}\right]+\mathrm{H}_{2} \mathrm{O}}$

determined by the variable heating rate method proposed by Flynn and Wall [31]; full experimental details of this method have also been given in ref. 32. The average $\mathrm{E}_{\mathrm{a}}$ values are $69.4 \mathrm{KJ} \mathrm{mol}^{-1}$ for 2 and $57.5 \mathrm{KJ} \mathrm{mol}^{-1}$ for 3. These values are characteristic of the removal of crystal water $[11,14,33]$. By differential scanning calorimetry (DSC) at a heating rate of $5^{\circ} \mathrm{C} \mathrm{min}^{-1}$ we have also measured the enthalpy of dehydration of $\mathbf{2}$ and $\mathbf{3}$. The $\Delta \mathrm{H}$ values were found to be $31.6(2)$ and 26.9 (3) $\mathrm{KJ} \mathrm{mol}^{-1}$; these values are in the region expect- 
ed for the removal of crystal $\mathrm{H}_{2} \mathrm{O}[11,14,34]$. The complexes decompose above $\mathrm{ca} .280{ }^{\circ} \mathrm{C}$ with rather simple degradation mechanisms, as revealed by the small number of DTG peaks, and without formation of stable intermediates; however, compound 5 explodes at $c a .250^{\circ} \mathrm{C}$.

Table I gives diagnostic $I R$ and far-IR bands. The assignments have been made by comparison with the data obtained for metal complexes with the same [21-27] or similar [8-18,35,36] ligands; the assignments for $\mathrm{LH}_{2}$ and complex 1 were assisted by deuterium isotopic substitution, which highlights any absorption associated with the $\mathrm{N}-\mathrm{H}$ bonds. Assignments of metal-ligand stretching vibrations have been made by noting: (i) the frequencies of the internal modes of $\mathrm{LH}_{2}, \mathrm{Py}$ and Mebta in the far-IR region; (ii) the variation in band frequency with changing the axial ligand in 2-5, and (iii) extensive literature reports [37-39].

In the $v(\mathrm{OH})_{\text {water }}$ region, the spectra of $\mathbf{2}$ and $\mathbf{3}$ show one medium and continuous absorption covering the $3500-3300 \mathrm{~cm}^{-1}$ region, which is attributed to the presence of lattice water [40]. Dehy- dration of these complexes at $c a .150{ }^{\circ} \mathrm{C}$ causes the disappearance of the band confirming its origin.

The perchlorate compounds $\mathbf{4}$ and $\mathbf{5}$ show very strong bands due to the $v_{3}\left(\mathrm{~F}_{2}\right)$ and $v_{4}\left(\mathrm{~F}_{2}\right)$ modes of the uncoordinated (ionic) $\mathrm{T}_{\mathrm{d}} \mathrm{ClO}_{4}^{-}$near 1100 and $620 \mathrm{~cm}^{-1}$, respectively [37].

The IR spectrum of Mebta exhibits two bands at 1197 and $1110 \mathrm{~cm}^{-1}$, which can be associated with the $v(\mathrm{~N}=\mathrm{N})$ and $v(\mathrm{~N}-\mathrm{N})$ modes of vibration, respectively [41]. These bands are shifted to higher frequencies in 5. Both shifts are compatible with $\mathrm{N}(3)$ of Mebta being the donor atom to rhodium(III) [41].

The IR spectrum of $\mathrm{LH}_{2}$ shows the characteristic bands of trans secondary amide groups with 2-pyridyl residues [22]. The absence of large shifts of the $v(\mathrm{~N}-\mathrm{H})$ and amide $\mathrm{V}$ bands in the spectrum of $\mathbf{1}$, in comparison with these bands in $\mathrm{LH}_{2}$, confirms the inability of the amide nitrogen to participate in coordination, if non-deprotonated. The amide I band shifts to a lower frequency, while the amide II and III bands shift to higher frequencies in 1 ; these shifts indicate amide-O coordination

Table I. Diagnostic IR and far-IR bands ${ }^{\mathrm{a}}\left(\mathrm{cm}^{-1}\right)$ of $\mathrm{LH}_{2}$ and its rhodium(III) complexes.

\begin{tabular}{|c|c|c|c|c|c|c|}
\hline Assignments & $\mathrm{LH}_{2}$ & 1 & 2 & 3 & 4 & 5 \\
\hline $\begin{array}{l}v(\mathrm{OH})_{\text {cryst. } \mathrm{H}_{2} \mathrm{O}} \\
v(\mathrm{~N}-\mathrm{H}) \\
v(\mathrm{C}=\mathrm{N})\end{array}$ & $3285 \mathrm{~s}$ & $3245 \mathrm{~m}$ & $3510-3300 \mathrm{mb}$ & $\begin{array}{l}3480-3300 \mathrm{mb} \\
2137 \mathrm{~s}\end{array}$ & & \\
\hline Amide $\mathrm{I}^{\mathrm{b}}$ & 1669 vs & $1623 \mathrm{vs}$ & $1617 \mathrm{~s}$ & $1621 \mathrm{vs}$ & 1627 vs & $1625 \mathrm{~s}$ \\
\hline Amide II $^{\mathrm{c}}$ & $1519 \mathrm{~m}$ & $1528 \mathrm{~s}$ & & & & \\
\hline $\begin{array}{l}v(\mathrm{C}-\mathrm{N})_{\text {amide }} \\
\text { Amide III }{ }^{\mathrm{c}}\end{array}$ & $1278 \mathrm{~m}$ & $1292 \mathrm{~m}$ & 1395 vs & $1386 \mathrm{~s}$ & $1390 \mathrm{~s}$ & $1392 \mathrm{~s}$ \\
\hline $\begin{array}{l}v(\mathrm{~N}=\mathrm{N})_{\text {Mebta }} \\
v(\mathrm{~N}-\mathrm{N})_{\mathrm{Mebta}}\end{array}$ & & & & & & $\begin{array}{l}1225 \mathrm{vs}^{\mathrm{e}} \\
1131 \mathrm{~m}^{\mathrm{e}}\end{array}$ \\
\hline $\begin{array}{l}v_{3}\left(\mathrm{ClO}_{4}^{-}\right) \\
\text {Amide } \mathrm{V}^{\mathrm{d}}\end{array}$ & $658 \mathrm{sb}$ & $665 \mathrm{mb}$ & & & 1098 vsb & $1100 \mathrm{vsb}$ \\
\hline $\begin{array}{l}\delta\left(2^{\prime} \text {-pyridyl rings }\right) \\
\delta(\mathrm{Py})\end{array}$ & $622 \mathrm{~m}$ & $657 \mathrm{~m}$ & $654 \mathrm{~m}$ & $658 \mathrm{~m}$ & $\begin{array}{l}659 \mathrm{~m} \\
647 \mathrm{~m}\end{array}$ & $655 \mathrm{~s}$ \\
\hline $\begin{array}{l}v_{4}\left(\mathrm{ClO}_{4^{-}}\right) \\
v(\mathrm{Rh}-\mathrm{C})\end{array}$ & & & & $479 \mathrm{~m}$ & $618 \mathrm{vs}$ & $621 \mathrm{vs}$ \\
\hline $\begin{array}{l}v\left(\mathrm{Rh}-\mathrm{N}_{\text {amide }}\right) \\
v\left(\mathrm{Rh}-\mathrm{O}_{\text {amide }}\right)\end{array}$ & & $469 w, 463 w$ & $471 \mathrm{~m}, 444 \mathrm{~m}$ & $461 \mathrm{mb}, 448 \mathrm{w}$ & $468 \mathrm{~m}, 440 \mathrm{w}$ & $470 \mathrm{~m}, 447 \mathrm{w}$ \\
\hline $\begin{array}{l}\gamma\left(2^{\prime} \text {-pyridyl rings }\right) \\
\gamma(\mathrm{Py})\end{array}$ & $410 \mathrm{~m}$ & $455 \mathrm{~m}$ & $458 w$ & $461 \mathrm{mb}^{\mathrm{f}}$ & $\begin{array}{l}459 \mathrm{~m} \\
452 \mathrm{~m}\end{array}$ & $460 \mathrm{~m}$ \\
\hline $\begin{array}{l}v\left(\mathrm{Rh}-\mathrm{N}_{\mathrm{Mebta}}\right) \\
v(\mathrm{Rh}-\mathrm{Cl})_{\mathrm{t}}\end{array}$ & & 327 vs & 324 vs & & & $345 w$ \\
\hline $\begin{array}{l}v\left(\mathrm{Rh}-\mathrm{N}_{\text {ring }}\right) \\
v\left(\mathrm{Rh}-\mathrm{N}_{\mathrm{Py}}\right)\end{array}$ & & $273 \mathrm{~m}, 264 \mathrm{~m}$ & $287 \mathrm{~m}, 276 \mathrm{w}$ & $284 \mathrm{~m}, 272 \mathrm{~m}$ & $\begin{array}{l}280 \mathrm{mb} \\
246 \mathrm{~m}\end{array}$ & $286 \mathrm{w}, 273 \mathrm{w}$ \\
\hline
\end{tabular}

${ }^{a}$ Fourier-transform spectra; ${ }^{\mathrm{b}} v(\mathrm{CO}) ;{ }^{\mathrm{c}}$ in secondary amides these bands arise from $v(\mathrm{C}-\mathrm{N})$ and $\delta(\mathrm{NH})$ modes; ${ }^{\mathrm{d}} \pi(\mathrm{NH}) ;{ }^{\mathrm{e}}$ overlapping with a ligand band; ${ }^{\mathrm{f}}$ overlapping. vs $=$ very strong, $\mathrm{s}=\mathrm{strong}, \mathrm{m}=\mathrm{medium}, \mathrm{w}=\mathrm{weak}, \mathrm{b}=$ broad, $\gamma=$ out-of-plane deformation, $\delta=$ in-plane deformation, $v(\mathrm{Rh}-\mathrm{Cl})_{\mathrm{t}}$ is the stretching vibration of the terminal $\mathrm{Rh}-\mathrm{Cl}$ bond, $\mathrm{Py}=$ pyridine and Mebta $=1$-methylbenzotriazole. 
$[35,36]$. Differences between the spectra of $\mathbf{1}$ and 2-5 are readily observable. Importantly, the $v(\mathrm{~N}-\mathrm{H})$ and amide $\mathrm{V}$ bands are absent in the spectra of 2-5, as expected from the stoichiometry. In addition the amide II and III peaks have been replaced by a strong band at $c a .1390 \mathrm{~cm}^{-1}$, which is characteristic for deprotonated secondary amide complexes $[11,25,35,36]$. This replacement is to be expected, as the removal of the amide proton produces a pure $\mathrm{C}-\mathrm{N}$ vibrational stretching mode. As has been shown previously for complexes of neutral secondary amides [35], the presence of both coordinated and uncoordinated amide groups in a compound is indicated by the considerably more complicated IR spectrum obtained. The observation of only one sharp absorption for each amide I, II and III band in the spectrum of $\mathbf{1}$ indicates that both amide groups are coordinated.

In the spectra of 1, 2, 3 and 5, the in-plane and out-of-plane deformation bands of the 2'-pyridyl ring shift to higher frequencies to indicate coordination of both ring $\mathrm{N}$-atoms [42]. These characteristic bands are doubled in the spectrum of $\mathbf{4}$, due to the presence of two different pyridine rings. Since the four bands are significantly shifted to higher frequences from their positions in the free $\mathrm{LH}_{2}$ and Py spectra, the implication is that all heterocyclic nitrogens of $\mathbf{4}$ are coordinated [11,16].

The spectrum of $\mathbf{3}$ exhibits the $v(\mathrm{C}=\mathrm{N})$ mode in the region characteristic of terminal C-bonded cyano groups [37]. In addition to this mode, the cyano complex exhibits the $v(\mathrm{Rh}-\mathrm{C})$ band in the low frequency region; the frequency of the $v(\mathrm{Rh}-\mathrm{C})$ mode is consistent with an octahedral environment around the metal $[37,39]$. The very strong bands at 327 and $324 \mathrm{~cm}^{-1}$ in the far-IR spectra of 1 and 2, respectively, arise from the terminal $\mathrm{Rh}^{\mathrm{III}}-\mathrm{Cl}$ stretching vibration in an octahedral environment $[37,39]$. It is quite clear that the position of $v(\mathrm{Rh}-\mathrm{Cl})$ rules out the possibility of bridging chloro ligands [39]. The appearance of one $v(\mathrm{Rh}-$ $\mathrm{Cl})_{\mathrm{t}}$ in each spectrum indicates that the two chloro ligands are trans to each other [37]. The presence of two $v\left(\mathrm{Rh}-\mathrm{N}_{\text {amide }}\right)$ and two $v\left(\mathrm{Rh}-\mathrm{N}_{\text {ring }}\right)$ vibrations in the far-IR spectra of $\mathbf{2 - 5}$ confirms the cis arrangements of the amide and 2'-pyridyl nitrogens in the equatorial plane of these complexes [37].

Table II gives details of the solid-state electronic spectra and diagnostic ${ }^{1} \mathrm{H}$ NMR chemical shifts for the prepared complexes. The electronic spectra of Rh(III) complexes all show bands at 2187024570 and $26770-32400 \mathrm{~cm}^{-1}$; the spectra resemble those of other six-coordinate rhodium(III) compounds and are assigned as transitions from the ${ }^{1} \mathrm{~A}_{1 \mathrm{~g}}$ ground state to the ${ }^{1} \mathrm{~T}_{1 \mathrm{~g}}$ and ${ }^{1} \mathrm{~T}_{2 \mathrm{~g}}$ upper states in octahedral symmetry, in increasing order of energy $[38,43]$. The higher energy band is probably obscured by change-transfer absorptions and hence crystal field parameters can not be calculated [43]. The complexes $\mathbf{4}$ and $\mathbf{5}$ seem to exhibit a splitting of the first spin-allowed band; this splitting is characteristic of a tetragonal distortion arising from the different nature of $\mathrm{L}^{2-}$ and $\mathrm{Py}$ or Mebta [43]. However, an ${ }^{1} \mathrm{~A}_{1 \mathrm{~g}} \rightarrow{ }^{3} \mathrm{~T}_{2 \mathrm{~g}}$ (singlet-triplet, spin-forbidden transition) origin of the lower energy component of the visible band can not be ruled out [43].

The ${ }^{l} H$ NMR study was based on comparison with the data obtained for diamagnetic complexes with the same [25] or similar [19,35,36] ligands; as-

Table II. Characteristic solid-state ${ }^{\mathrm{a}, \mathrm{b}}$ electronic $\left(10^{3} \mathrm{~cm}^{-1}\right)$ and ${ }^{1} \mathrm{H}$ NMR $(\mathrm{ppm})^{\mathrm{b}}$ spectral data.

\begin{tabular}{|c|c|c|c|c|c|}
\hline \multirow[b]{2}{*}{ Compound } & \multicolumn{2}{|c|}{$\mathrm{UV} / \mathrm{VIS}^{\mathrm{c}}$} & \multicolumn{3}{|c|}{${ }^{1} \mathrm{H} \mathrm{NMR}^{\mathrm{d}, \mathrm{e}}$} \\
\hline & ${ }^{1} \mathrm{~A}_{1 \mathrm{~g}} \rightarrow{ }^{1} \mathrm{~T}_{1 \mathrm{~g}}$ & ${ }^{1} \mathrm{~A}_{1 \mathrm{~g}} \rightarrow{ }^{1} \mathrm{~T}_{2 \mathrm{~g}} / \mathrm{CT}$ & NH(amide) & $\mathrm{H}\left(6^{\prime}\right)$ & $J\left(\mathrm{H}^{5 \prime} \mathrm{H}^{6^{\prime}}\right)^{\mathrm{f}}$ \\
\hline 1 & $21.87 \mathrm{sh}$ & 26.77 & $10.34 \mathrm{~b}$ & $8.90 \mathrm{~d}$ & 5.6 \\
\hline 2 & 22.22 & 29.41 & & $9.11 \mathrm{~d}$ & 5.8 \\
\hline 3 & $23.53 \mathrm{sh}$ & 30.58 & & $9.05 \mathrm{~d}$ & 5.4 \\
\hline 4 & $22.57 \mathrm{sh}, 24.57$ & 32.05 & & $9.20 \mathrm{~d}$ & 5.6 \\
\hline 5 & $22.78 \mathrm{sh}, 24.47$ & 32.40 & & $9.17 \mathrm{~d}$ & 5.5 \\
\hline
\end{tabular}

${ }^{a}$ Diffuse reflectance spectra; ${ }^{b}$ spectra recorded at ambient temperature; ${ }^{c}$ assignments are given assuming a ligand field of $\mathrm{O}_{\mathrm{h}}$ symmetry; ${ }^{\mathrm{d}}$ chemical shifts with reference to $\mathrm{Me}_{4} \mathrm{Si}$ in $\mathrm{d}_{6}$-DMSO (1-3) or $\mathrm{CD}_{3} \mathrm{CN}(\mathbf{4 , 5})$ solutions; ${ }^{\text {e }}$ the spectra were run 15-20 min after dissolution; ${ }^{\mathrm{f}}$ coupling constants in $\mathrm{Hz} . \mathrm{b}=$ broad, $\mathrm{d}=$ doublet, $\mathrm{sh}=\mathrm{shoulder}$. 
signments for individual ring protons in $\mathbf{4}$ and $\mathbf{5}$ were also assisted by resonance decoupling studies. The occurrence of the $\mathrm{NH}$ signals at almost the same $\delta$ values in the spectra of $\mathbf{1}(10.34 \mathrm{ppm})$ and free $\mathrm{LH}_{2}(10.52 \mathrm{ppm})$ in $\mathrm{d}_{6}$-DMSO indicates the non-involvement of the neutral amide nitrogens in coordination; a large downfield shift would be expected if coordination had occurred.

As compared to the spectrum of free $\mathrm{LH}_{2}$ in various solvents, the naphthalene and 2'-pyridyl signals in the spectra of the complexes are slightly shifted to lower or higher fields; the changes in chemicals shifts are due to several effects, like the electric field caused by complexation, $\pi$-bonding and temperature-independent paramagnetism of the metal ion [44]. The most pronounced variation in chemical shift is the downfield shift of $\mathrm{H}\left(6^{\prime}\right)$ (in free $\mathrm{LH}_{2}$ this signal appears at $\delta 8.54$ and $8.56 \mathrm{ppm}$ in $\mathrm{d}_{6}$-DMSO and $\mathrm{CD}_{3} \mathrm{CN}$, respectively) indicating the participation of the nearest nitrogen atoms $\mathrm{N}\left(1^{\prime}\right)$ in metal coordination $[25,35,36]$. For complexes $\mathbf{2}-\mathbf{5}$, chemical shifts and coupling constants of naphthalene protons were found to be completely unaffected by the nature of the axial ligand.

The spectra of $\mathbf{4}$ and $\mathbf{5}$ are much more complicated than those of 1, $\mathbf{2}$ and $\mathbf{3}$ due to the presence of Py and Mebta as axial ligands. With regard to compound 5, the ${ }^{1} \mathrm{H}$ NMR spectrum of free Mebta in $\mathrm{CD}_{3} \mathrm{CN}$ shows signals at $\delta$ 4.34(s), 7.45(t), $7.59(\mathrm{t}), 7.84(\mathrm{~d})$ and $8.03(\mathrm{~d})$ due to $\mathrm{CH}_{3}, \mathrm{H}(5)$, $\mathrm{H}(6), \mathrm{H}(7)$ and $\mathrm{H}(4)$, respectively [45]. The signal of $\mathrm{H}(4)$ shifts downfield ( $c a .0 .25 \mathrm{ppm}$ ) compared with the free triazole, suggesting that the azole$\mathrm{N}(3)$ atom is coordinated to Rh(III) [45].

Complexes 2, 3 and $\mathbf{4}$ were studied by using the cyclic voltammetry $(\mathrm{CV})$ technique in $\mathrm{MeCN}$. Data are summarized in Table III. Unfortunately, the insoluble nature of the rhodium complex of neutral $\mathrm{LH}_{2}$ prevented comparison with the $\mathrm{CV}$ data of the deprotonated complexes. Complex 5 displayed complicated, broad, ill-defined and irreversible features, presumably because of the noninnocent redox behaviour of Mebta.

The $\mathrm{CV}$ examination of $\mathbf{2}$ in $\mathrm{MeCN}$ reveals the presence of two oxidation couples at +0.37 and $+0.94 \mathrm{~V}$ ( $v s$. ferrocenium-ferrocene) and one reduction couple at $E_{p}$ of $-2.00 \mathrm{~V}$. The peak separation $\Delta \mathrm{E}_{\mathrm{p}}$ for each oxidation couple is close to that anticipated for a Nerstian one-electron process $(59 \mathrm{mV})$; plots of peak current $v s . v(v=$ scan rate $)$ in the $20-200 \mathrm{mV} \mathrm{s}^{-1}$ are linear, and the ratio of the cathodic to anodic peak currents is very close to one, indicating that electron transfer is reversible and that mass transfer is limited [46]. The reduction couple $\left(\mathrm{Rh}^{\mathrm{III}}+\mathrm{e} \rightarrow \mathrm{Rh}^{\mathrm{II}}\right)$ is irreversible. Complexes $\mathbf{3}$ and $\mathbf{4}$ show a similar CV behaviour; however, the second oxidation reaction is irreversible. The increase in the oxidation potential values parallels the increase in the charge on the complex from -1 to +1 . Complexes $\mathbf{2}$ and $\mathbf{3}$, which bear the same charge, have a small difference in the formal oxidation potential. This probably indicates the dominance of the potential-energy terms over the effect of the donor strength of the axial ligands [19].

The relative insensitivity of the first oxidation couple of the anionic complexes $\mathbf{2}$ and $\mathbf{3}$ to the nature of the axial ligand, the high stability of their one-electron oxidized products and literature reports [19] for $\mathrm{Rh}$ (III) complexes with similar dianionic, pyridine-containing, bis-amide tetradentate ligands suggest that the first oxidation couple

Table III. Cyclic voltammetric data ${ }^{\mathrm{a}, \mathrm{b}, \mathrm{c}}$ for the rhodium(III) complexes $\mathbf{2 ,} \mathbf{3}$ and $\mathbf{4}$ in $\mathrm{MeCN}$.

\begin{tabular}{|c|c|c|c|c|c|c|}
\hline \multirow[b]{2}{*}{ Complex } & \multicolumn{2}{|c|}{ 1st oxidation } & \multicolumn{2}{|c|}{ 2nd oxidation } & \multicolumn{2}{|c|}{ 1st reduction } \\
\hline & $\mathrm{E}^{\mathrm{o} / \mathrm{d}}$ & $\mathrm{i}_{\mathrm{pc}} / \mathrm{i}_{\mathrm{pa}}$ & $\mathrm{E}^{\mathrm{o} / \mathrm{d}}\left(\mathrm{E}_{\mathrm{pa}}^{\mathrm{e}}\right)$ & $\mathrm{i}_{\mathrm{pa}^{2}} / \mathrm{i}_{\mathrm{pa} \mathrm{f}^{\mathrm{f}}}$ & $\mathrm{E}_{\mathrm{pc}}^{\mathrm{e}}$ & $\mathrm{i}_{\mathrm{pc}} / \mathrm{i}_{\mathrm{pa}(\mathrm{ox})} \mathrm{g}^{\mathrm{g}}$ \\
\hline 2 & +0.37 & 1.04 & +0.94 & 0.88 & -2.00 & 1.43 \\
\hline 3 & +0.48 & 1.01 & $(+1.04)$ & 1.12 & -2.35 & 1.61 \\
\hline 4 & +0.80 & 0.92 & $(+1.26)$ & 2.01 & -1.78 & 1.76 \\
\hline
\end{tabular}

${ }^{a}$ Cyclic voltammograms were recorded using a standard three-electrode assembly (glassy-carbon working, Pt-wire auxiliary, SCE reference) and $0.1 \mathrm{M} \mathrm{NBu}_{4}{ }^{n} \mathrm{BF}_{4}$ as supporting electrolyte; ${ }^{\mathrm{b}}$ the scan rate was $100 \mathrm{mV} \mathrm{s}{ }^{-1}$ and no IR compensation employed; ${ }^{c}$ potentials are quoted vs. the ferrocene/ferrocenium couple; ${ }^{d} \mathrm{E}^{\mathrm{o} /}$ is given for reversible couples; ${ }^{\mathrm{e}}$ these potentials are reported for irreversible couples; ${ }^{\mathrm{f}} \mathrm{i}_{\mathrm{pa}}{ }^{1}$ and $\mathrm{i}_{\mathrm{pa}}{ }^{2}$ are the peak currents of the first and second oxidation peaks, respectively; $\mathrm{g}_{\mathrm{pc}}$ and $\mathrm{i}_{\mathrm{pa}(\mathrm{ox})}$ are the peak currents of the reduction and the first oxidation couple, respectively. 
is largely ligand- and not metal-centred. Although $\mathrm{LH}_{2}$ only gives an irreversible oxidation peak at a much more anodic potential ( $c a$. $1 \mathrm{~V} v s$. ferrocenium-ferrocene), it has been established [19] that coordination to metal and deprotonation of the amide groups can cause analogous ligands to be oxidized at a less anodic potential. Che and co-workers [19] have shown that the axial ligand exerts its effect through the central metal electron density which in turn affects the energy levels and electron density on the equatorial ligand; thus, the redox oxidation couple is mainly ligand-centred but has a certain degree of metal character. The second oxidation couple of $\mathbf{2 , 3}$ and $\mathbf{4}$ is attributed to $\mathrm{Rh}^{\mathrm{III}} \rightarrow \mathrm{Rh}^{\mathrm{IV}}+\mathrm{e}^{-}$, with the generated $\mathrm{Rh}(\mathrm{IV})$ species being unstable. Efforts to characterize the one- and two-electron oxidized species using ESR and UV/VIS spectroscopies are in progress.

From the overall study presented above, it is concluded that $\mathbf{1}$ almost certainly has the oligomeric or polymeric, octahedral structure shown in III. Thus each molecule of $\mathrm{LH}_{2}$ would act as a bisbidentate ligand coordinating through both pyridyl-N and amide-O atoms and bridging two metal ions. Molecular models show that such a structure is quite feasible. This form of coordination would allow a considerable amount of hydrogen bonding, accounting for the low solubility of this ionic complex. Although trans conformations of the four ligand donor atoms can not be discounted, the appearance of two $v\left(\mathrm{Rh}-\mathrm{N}_{\text {ring }}\right)$ and two $v\left(\mathrm{Rh}-\mathrm{O}_{\text {amide }}\right)$ bands in the far-IR spectrum suggests a cis arrangement.

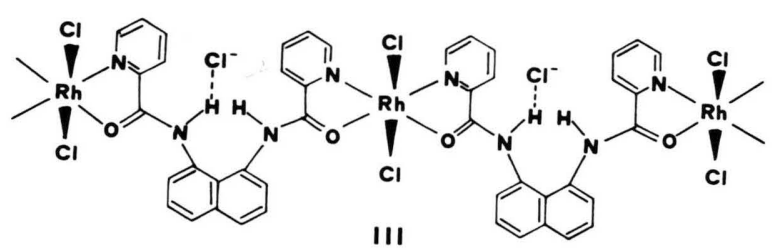

Complexes 2-5 have a low-spin, monomeric octahedral stereochemistry (IV). The nitrogen atoms of the chelating tetradentate dianionic ligand $\mathrm{L}^{2-}$ seem to adopt an essentially planar arrangement about rhodium(III), with the remaining axial coordination sites occupied by chloro(2), cyano(3), pyridine(4) or 1-methylbenzotriazole(5) ligands. Amide deprotonation leads to systems having a considerable degree of delocalization.

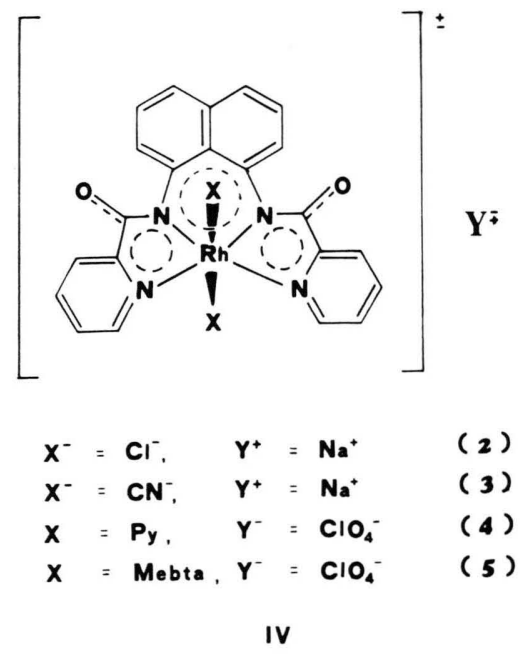

The results described in this report represent the initial study of the coordination chemistry of polydentate amide ligands with $4 \mathrm{~d}$ and $5 \mathrm{~d}$ metals; further studies are in progress and iridium and gold species at various oxidation states are under characterization.

We wish to thank Prof. H. O. Desseyn and Prof. N. Hadjiliadis for providing some instrumental facilities (thermal, far-IR) and elemental analyses, respectively. We also thank Dr. J. C. Plakatouras for assistance and usefull advice with cyclic voltammetry and NATO for partial support of this work. 
[1] H. Sigel, R. B. Martin, Chem. Rev. 82, 385 (1982).

[2] F. C. Anson, T. J. Collins, S. L. Gipson, J. T. Keech, T. E. Krafft, G. T. Peake, J. Am. Chem. Soc. 108, 6593 (1986), and refs. therein.

[3] M.-S. Chao, C.-S. Chung, Inorg. Chem. 28, 686 (1989)

[4] A. Stassinopoulos, G. Schulte, G. C. Papaefthymiou, J. P. Caradona, J. Am. Chem. Soc. 113, 8686 (1991).

[5] S. J. Brown, S. E. Hudson, D. W. Stephan, P. K. Mascharak, Inorg. Chem. 28, 468 (1989), and refs. therein.

[6] A. Escuer, R. Vicente, J. Ribas, R. Costa, X. Solans, ibid. 31, 2627 (1992).

[7] O. Guillou, O. Kahn, R. L. Oushoorn, K. Boubekeur, P. Batail, Inorg. Chim. Acta 198-200, 119 (1992).

[8] Th. Kabanos, S. P. Perlepes, V. Hondrellis, J. M. Tsangaris, Monatsh. Chem. 117, 955 (1986).

[9] S. P. Perlepes, Th. Kabanos, V. Lazaridou, J. M. Tsangaris, Inorg. Chim. Acta 117, 27 (1986).

[10] V. Hondrellis, Th. Kabanos, S. P. Perlepes, J. M. Tsangaris, ibid. 136, 1 (1987).

[11] S. P. Perlepes, Th. Kabanos, V. Hondrellis, J. M. Tsangaris, ibid. 150, 13 (1988).

[12] S. P. Perlepes, V. Lazaridou, J. M. Tsangaris, Synth. React. Inorg. Met.-Org. Chem. 19, 841 (1989).

[13] F. J. Quaeyhaegens, S. P. Perlepes, H. O. Desseyn, Spectrochim. Acta, Part A45, 809 (1989).

[14] V. Lazaridou, S. P. Perlepes, J. M. Tsangaris, J. Less-Common Metals 158, 1 (1990).

[15] F. J. Quaeyhaegens, H. O. Desseyn, S. P. Perlepes, J. C. Plakatouras, B. Bracke, A. T. H. Lenstra, Transition Met. Chem. 16, 92 (1991).

[16] Th. F. Zafiropoulos, J. C. Plakatouras, S. P. Perlepes, Polyhedron 10, 2405 (1991).

[17] S. P. Perlepes, V. Hondrellis, J. M. Tsangaris, U. Russo, Inorg. Chim. Acta 189, 213 (1991).

[18] G. Maistralis, N. Katsaros, S. P. Perlepes, D. Kovala-Demertzi, J. Inorg. Biochem. 45, 1 (1992).

[19] S.-T. Mak, V.W.-W. Yam, C.-M. Che, T. C. W. Mak, J. Chem. Soc. Dalton Trans. 1990, 2555.

[20] T. J. Collins, B. D. Santarsiero, G. H. Spies, J. Chem. Soc., Chem. Commun. 1983, 681.

[21] J. M. Tsangaris, S. P. Perlepes, A. G. Galinos, Z. Naturforsch. 34b, 456 (1979).

[22] Th. F. Zafiropoulos, S. P. Perlepes, P. V. Ioannou, J. M. Tsangaris, A. G. Galinos, ibid. 36b, 87 (1981).

[23] A. G. Galinos, S. P. Perlepes, Th. F. Zafiropoulos, P. V. Ioannou, J. K. Kouinis, Monatsh. Chem. 112, $1113(1981)$.

[24] Th. F. Zafiropoulos, S. P. Perlepes, A. G. Galinos, Chem. Scripta 20, 237 (1982).
[25] S. P. Perlepes, Th. A. Kabanos, J. M. Tsangaris, Bull. Soc. Chim. Belg. 92, 859 (1983).

[26] S. P. Perlepes, A. G. Galinos, J. Less-Common Metals 96, 69 (1984)

[27] Th. F. Zafiropoulos, S. P. Perlepes, J. M. Tsangaris, J. Coord. Chem. 14, 87 (1985).

[28] Th. F. Zafiropoulos, J. C. Plakatouras, S. P. Perlepes, Z. Naturforsch. 46b, 1532 (1991)

[29] G. Christou, S. P. Perlepes, E. Libby, K. Folting, J. C. Huffman, R. J. Webb, D. N. Hendrickson, Inorg. Chem. 29, 3657 (1990).

[30] W. J. Geary, Coord. Chem. Rev. 7, 81 (1971).

[31] J. H. Flynn, L. A. Wall, Polym. Lett. 4, 323 (1966).

[32] S. P. Perlepes, P. Jacobs, H. O. Desseyn, J. M. Tsangaris, Spectrochim. Acta, Part A 43, 771 (1987).

[33] S. Kumar, S. K. Gupta, S. K. Sharma, Thermochim. Acta 71, 193 (1983).

[34] B. W. Delf, R. D. Gillard, P. O’Brien, J. Chem. Soc. Dalton Trans. 1979, 1301.

[35] D. J. Barnes, R. L. Chapman, F. S. Stephens, R. S. Vagg, Inorg. Chim. Acta 51, 155 (1981), and refs. therein.

[36] R. L. Chapman, F. S. Stephens, R. S. Vagg, ibid. 52, 161 (1981)

[37] K. Nakamoto, Infrared and Raman Spectra of Inorganic and Coordination Compounds, 4th ed., pp. 191-208, 251, 272-280, 324-331, Wiley, New York (1986).

[38] M. S. Islam, M. M. Uddin, Polyhedron 12, 423 (1993).

[39] D. M. Adams, Metal-Ligand and Related Vibrations, pp. 65, 69, 71, 169, 170, 172, 308, Arnold, London (1967).

[40] L. S. Gelfand, F. J. Iaconianni, L. L. Pytlewski, A. N. Speca, C. M. Mikulski, N. M. Karayannis, J. Inorg. Nucl. Chem. 42, 377 (1980).

[41] J. C. Plakatouras, S. P. Perlepes, D. Mentzafos, A. Terzis, T. Bakas, V. Papaefthymiou, Polyhedron 11, 2657 (1992)

[42] R. J. H. Clark, C. S. Williams, Inorg. Chem. 4, 350 (1965).

[43] A. B. P. Lever, Inorganic Electronic Spectroscopy, 2nd ed., pp. 457, 458, 464, 465, 478, Elsevier, Amsterdam (1984).

[44] C. G. van Kralingen, J. K. de Ridder, J. Reedijk, Transition Met. Chem. 5, 73 (1980).

[45] D. Kovala-Demertzi, S. P. Perlepes, ibid., in press (1993), and refs. therein.

[46] E. R. Brown, J. R. Sandifer, in B. W. Rossiter, J. F. Hamilton (eds): Physical Methods of Chemistry, Vol. II: Electrochemical Methods, 2nd ed., pp. $273-277,281-375$. 